\title{
Rancang Bangun Secure Mobile IP PBX Berbasis Raspberry Pi Dalam Mendukung Komunikasi Kegiatan Luar Taruna Akademi Angkatan Udara
}

\author{
(Raspberry Pi Based Secure Mobile IP PBX Design to Support \\ Outdoor Activities Communication for Air Force Academy \\ Cadets)
}

\author{
M. Kharrel Dwiadamajati ${ }^{1}$, M. Fahrurozi ${ }^{2}$, Edi Supartono ${ }^{3}$, Bambang Gastomo ${ }^{4}$ \\ 1,2,3,4 Teknik Elektro, Akademi Angkatan Udara \\ E-mail: kharrel.dwiadamajati@aau.ac.id,muhammad.fahrurozi@aau.ac.id,edi.supartono@aau.ac.id, \\ bambang.gastomo@aau.ac.id
}

\begin{abstract}
The Air Force Academy is a candradimuka crater for prospective soldiers who will later produce Air Force officers who are Tanggon, Responsive and Trengginas. In their activities they carry out learning and practicing activities both inside and outside the knighthood. Outdoor activities are carried out in a field full of challenges. Under any circumstances and under any conditions the activity must be carried out properly. Communication is one of the main keys to the success of a mission. In this study, a secure mobile IP PBX based on raspberry pi 4. This VoIP server replaces the conventional $P A B X$ and is used as a means of communication even though there is no internet signal. The device is designed as a standalone PABX field that is not dependent on a particular vendor. The user uses a softphone that is embedded in the smartphone. In addition, the security side remains the main factor in maintaining the content of the communication content. This device is equipped with TLS and ZRTP protocols to prevent MiTM attacks from occurring. In the end, this device is a communication bridge when $A A U$ cadets are carrying out external activities.
\end{abstract}

Keywords-IP PBX, raspberry pi, VoIP, ZRTP, MiTM

Abstrak - Akademi Angkatan Udara merupakan kawah candradimuka bagi calon prajurit yang nantinya akan mencetak perwira Angkatan Udara yang Tanggon, Tanggap dan Trengginas. Dalam kegiatannya mereka melaksanakan kegiatan belajar dan berlatih baik didalam maupun diluar ksatrian. Kegiatan luar dilaksanakan dalam medan yang penuh dengan tantangan. Dalam keadaan bagaimanapun dan kondisi apapun kegiatan harus terlaksana dengan baik. Komunikasi merupakan salah satu kunci utama keberhasilan sebuah misi. Dalam penelitian ini dibuat secure mobile IP PBX berbasis raspberry pi 4. Server VoIP ini menggantikan PABX konvensional dan sebagai sarana komunikasi meskipun tidak ada sinyal internet. Perangkat yang didesain mandiri sebagi PABX lapangan yang tidak tergantung pada sebuah vendor tertentu. User menggunakan softphone yang tertanam pada smartphone. Selain itu sisi keamanan tetap menjadi faktor utama dalam menjaga kandungan isi komunikasi. Perangkat ini dilengkapi dengan protokol TLS dan ZRTP untuk mencegah terjadinya serangan MiTM. Pada akhirnya perangkat ini merupakan sebuah jembatan komunikasi pada saat Taruna AAU sedang melaksanakan kegiatan luar.

Kata Kunci-IP PBX, raspberry pi, VoIP, ZRTP, MiTM

*Penulis Korespondensi (M. Kharrel Dwiadamajati)

E-mail: kharrel.dwiadamajati@aau.ac.id 


\section{Pendahuluan}

A kademi Angkatan Udara merupakan organisasi atau badan pelaksana pusat pada tingkat Mabesau yang berkedudukan langsung di bawah Kasau. Selain itu AAU bertugas menyelenggarakan pendidikan pertama perwira sukarela TNI Angkatan Udara tingkat akademik [1]. AAU menjadikan perguruan tinggi yang mempunyai keunggulan dalam bidang iptek kedirgantaraan bertaraf internasional, berkarakter, mempunyai integritas tinggi, professional dan berwawasan kebangsaan [2]. Kegiatan belajar dan mengajar yang diselenggarakan tidak hanya didalam ksatrian AAU. Taruna AAU juga mendapatkan materi kegiatan yang pelaksanaannya diluar ksatrian seperti Latihan Terjun Para Dasar, Latihan Bhuwana Paksa, Latihan Wanatirta, Latihan Cakra Wahana Paksa dan Latihan Integrasi Taruna Wreda Nusantara. Setiap kegiatan membutuhkan dukungan dari semua pihak tidak terkecuali kelancaran dalam berkomunikasi. Dengan demikian kelancaran komunikasi merupakan salah satu kunci sukses suatu pelaksanaan kegiatan. Dalam dunia komunikasi militer, tidak hanya membutuhkan perangkat komunikasi yang handal namun tetap mengedepankan faktor kerahasiaan agar kandungan informasi tetap terjaga. Dalam berkomunikasi dibutuhkan suatu media salah satunya berupa sentral telepon. Dalam perkembangan telekomunikasi sekarang ini khususnya telepon, kita mengenal istilah VoIP (Voice over Internet Protocol). VoIP merupakan komunikasi suara yang dibangun menggunakan internet atau jaringan IP. Aplikasi ini dikenal juga dengan nama telepon IP atau telepon broadband. Sistem VoIP ini memberikan beberapa keuntungan diantaranya sedikit menggunakan perkabelan sehingga dapat menghilangkan kerumitan kabel (spaghetti cables) dan biaya yang lebih ekonomis dibandingkan dengan sistem konvensional [3].

Kegiatan luar Taruna seperti yang telah disebutkan diatas perlu mendapatkan dukungan dari seluruh stakeholder yang ada tidak terkecuali dari pihak penyelenggara komunikasi. Kondisi lapangan saat latihan yang penuh dengan tantangan seperti kontur perbukitan, gunung, hutan, sungai dan pantai serta pada saat mereka di sedang berlayar ditengah lautan menggunakan KRI. Ketersediaan jaringan intenet disuatu tempat yang tidak menentu serta kekuatan sinyalnya yang tidak bisa diandalkan. Hal tersebut merupakan sebagian tantangan yang harus diatasi dalam mendukung kelancaran kegiatan Taruna. Selain itu dengan semakin canggihnya teknologi komunikasi berupa VoIP ternyata berbanding lurus dengan banyaknya resiko keamanan yang muncul [4]. Pelanggaran keamanan (security breach) dalam dunia komunikasi VoIP diantaranya DoS (Denial of Service) attacks. Penyerangan dengan tujuan melakukan kerentanan pada jaringan protokol komunikasi atau menghabiskan sumber daya lawan merupakan serangan DoS (Denial of Services) dan DDoS (Distributed Denial of Services). Hal ini bertujuan memotong layanan komputer atau jaringan dan membuat sistem lawan gagal untuk merespon bahkan tidak berfungsi [5]. Selain itu beberapa serangan pada VoiP yang terjadi diantaranya adalah interception of private communication, registration hijacking, spam dan message tampering [6]. Menguping (eavesdropping) dan mengendus (sniffing) pada percakapan komunikasi VoIP merupakan tindakan para peretas untuk mendapatkan informasi yang diinginkan dengan cara menangkap, merekontruksi dan memainkan percakapan VoIP di Internet. Dalam mendapatkan percakapan VoIP ini dilakukan tanpa otentikasi [5].

Tujuan dari penelitian ini untuk menjawab tantangan pada permasalahan diatas dengan merancang server berbasis raspberry pi menggunakan softswitch asterisk. IP PBX lapangan berbasis raspberry pi merupakan pilihan yang didesain sesuai dengan kebutuhan dilapangan. Mandiri dan tidak bergantung dengan brand tertentu sehingga dapat mengurangi terjadinya pelanggaran keamanan (security hole). Server VoIP portabel ini berfungsi seperti PABX pada umumnya dan dilengkapi dengan protokol keamanan ZRTP dimana ZRTP menghasilkan shared secret antara initiator dan responder yang kemudian digunakan untuk menghasilkan kunci Secure RTP. Beberapa digit unik atau yang disebut dengan Short Autentication Strings (SAS) harus dibandingkan [7] dan dapat dilakukan dengan mengucapkan secara lisan [8]. Jika saat verifikasi SAS tersebut tidak sama antar pengguna, dapat dipastikan serangan sedang terjadi pada komunikasi VoIP tersebut. Dengan melakukan prosedur diatas maka serangan Man in The Middle (MiTM) dapat dihindar 


\section{LANDASAN TEORI}

\section{A. Raspberry pi}

Raspberry pi merupakan komputer yang berukuran sebesar kartu ATM . Jika dilihat dari ukurannya, parangkat yang luar biasa tersebut berukuran mini tetapi dapat menggantikan sebagai fungsi komputer. raspberry pi dikenal sebagai komputer papan tunggal, dapat berfungsi seperti desktop, laptop, maupun smartphone yang dibangun dan dicetak dalam satu papan sirkuit. Seperti kebanyakan komputer papan tunggal, raspberry pi berukuran kecil seukuruan kartu kredit tetapi raspberry pi dapat melakukan apa saja sebagai komputer. raspberry pi telah dirancang agar secepat dan semudah mungkin dalam pengaturan dan penggunaan. tetapi seperti komputer pada umumnya perangkat ini memerlukan pada beberapa komponen eksternal yang disebut periferal [9] [10].

Kini telah hadir raspberry pi 4 model b adalah produk terbaru dalam jajaran raspberry pi yang populer. Produk ini menawarkan peningkatan kecepatan prosesor, multimedia kinerja,memori, dan konektivitas dibandingkan dengan generasi sebelumnya raspberry pi 3 model b+. Untuk pengguna, raspberry pi 4 model b menyediakan desktop kinerja yang sebanding dengan sistem PC x86 entry-level [11].

TABEL I

SPESIFIKASI RASPBERRY PI 4

\begin{tabular}{|c|c|}
\hline Nama Media & Fungsi \\
\hline Processor & $\begin{array}{l}\text { Broadcom BCM2711, quad-core Cortex-A72 (ARM v8) 64-bit SoC @ } \\
1.5 \mathrm{GHz}\end{array}$ \\
\hline Memory & 1GB, 2GB, 4GB or 8GB LPDDR4 (depending on model) with on-die ECC \\
\hline Connectivity & $\begin{array}{l}2.4 \mathrm{GHz} \text { and } 5.0 \mathrm{GHz} \text { IEEE } 802.11 \mathrm{~b} / \mathrm{g} / \mathrm{n} / \mathrm{ac} \text { wireless } \\
\text { LAN, Bluetooth } 5.0 \text {, BLE } \\
\text { Gigabit Ethernet } \\
2 \times \text { USB } 3.0 \text { ports } \\
2 \times \text { USB } 2.0 \text { ports. }\end{array}$ \\
\hline GPIO & $\begin{array}{l}\text { Standard 40-pin GPIO header (fully backwards-compatible with previous } \\
\text { boards) }\end{array}$ \\
\hline Video \& sound & $\begin{array}{l}2 \times \text { micro HDMI ports (up to } 4 \mathrm{Kp} 60 \text { supported) } \\
\text { 2-lane MIPI DSI display port } \\
\text { 2-lane MIPI CSI camera port } \\
\text { 4-pole stereo audio and composite video port } \\
\end{array}$ \\
\hline Multimedia & $\begin{array}{l}\text { H.265 (4Kp60 decode); } \\
\text { H.264 (1080p60 decode, 1080p30 encode); } \\
\text { OpenGL ES, } 3.0 \text { graphics }\end{array}$ \\
\hline $\begin{array}{l}\text { SD card } \\
\text { support }\end{array}$ & Micro SD card slot for loading operating system and data storage \\
\hline Input power & $\begin{array}{l}\left.5 \mathrm{~V} \text { DC via } \mathrm{USB}-\mathrm{C} \text { connector (minimum } 3 \mathrm{~A}^{1}\right) \\
\left.5 \mathrm{~V} \text { DC via } \mathrm{GPIO} \text { header (minimum } 3 \mathrm{~A}^{1}\right) \\
\text { Power over Ethernet }(\mathrm{PoE})-\text { enabled } \\
\text { (requires separate } \mathrm{PoE} \mathrm{HAT})\end{array}$ \\
\hline Environment & Operating temperature $0-50^{\circ}$ \\
\hline Compliance & $\begin{array}{l}\text { For a full list of local and regional product approvals, please visit } \\
\text { https://www.raspberrypi.org/documentation/hardware/raspberrypi/conform } \\
\text { ity.md }\end{array}$ \\
\hline $\begin{array}{l}\text { Production } \\
\text { lifetime }\end{array}$ & $\begin{array}{l}\text { The Raspberry Pi } 4 \text { Model B will remain in production until at least } \\
\text { January } 2026 .\end{array}$ \\
\hline
\end{tabular}




\section{B. Asterisk}

Asterisk adalah PBX open-source yang memiliki kemampuan VoIP. Jadi siapapun bisa merancang IP PBX sesuai kebutuhan organisasinya dikarenakan sistem operasinya yang bersifat open-source berbasis linux. Penggunaanya dapat diintegrasikan dengan perangkat yang sudah ada sehingga jaringan sebelumnya yang sudah terpasang tetap bisa digunakan [12]. Saat ini, Asterisk adalah salah satu PBX VoIP berbasis perangkat lunak paling populer yang berjalan di beberapa sistem operasi. Asterisk menangani fitur PBX konvensional dan menggabungkan lebih banyak fitur yang didalamnya. Softswitch ini bekerja dengan protokol dan terhubung dengan VoIP sehingga banyak perangkat keras yang berinteraksi dengan jaringan telepon dapat diintegrasikan. Asterisk saat ini terdepan dalam penguasaan teknologi VoIP beberapa keuntungan dengan menggunakan perangkat ini adalah yang banyak dibicarakan karena rendahnya biaya, bersifat open-source, dan kemampuannya yang multifungsi [13]. Asterisk dan VoIP merupakan jembatan antara telepon konvensional dengan telepon menggunakan jaringan atau VoIP. VoIP sering dianggap sebagai sarana untuk melakukan telepon jarak jauh yang gratis. Tantangan sebenarnya dari VoIP adalah memungkinkan suara menjadi tidak lebih dari aplikasi lain dalam data jaringan.Tujuan komunikasi telepon adalah memungkinkan orang untuk berkomunikasi. Tujuan yang sederhana, dan mewujudkannya dengan cara yang lebih fleksibel dan kreatif dari perkembangan teknologi komunikasi [14].

\section{ZRTP (Zimmerman Realtime Transport Protocol)}

Zimmerman Realtime Transport Protocol adalah key agreement protocol dengan mengimplementasikan DH (Diffie Hellman) sebagai key exchange ditunjukkan pada Gambar 1 saat memulai panggilan VoIP dan menggunakan RTP (Realtime Transport Protocol) sebagai media transport yang telah diinisiasikan oleh signaling protocol seperti SIP (Session Initiation Protocol) yang akan menghasilkan shared secret [15]. ZRTP berperan sebagai pengaman komunikasi pada VoIP. ZRTP menggunakan AES 128-bit atau 256-bit bersama-sama dengan sistem pertukaran kunci 3072-bit [16]. Selanjutnya melaksanakan verifikasi berbasis suara untuk mencegah serangan man-in-the-middle [17]. ZRTP memiliki fitur kriptografi yang menarik dibandingkan dengan metode pada media session encryption yang lain. Proses pada ZRTP tidak berdasarkan pada PKI (Public Key Infrastructure) meskipun ZRTP menggunakan algoritma public key. Panggilan yang berlangsung sebelumnya akan ditampilkan beberapa kode unik harus dibandingkan secara verbal pada pengguna yang disebut dengan SAS (Short Authentication String) ZRTP menggunakan hasil hash dari DH. Pada panggilan berikutnya pengguna tidak akan direpotkan dengan SAS, ZRTP akan menyimpan key material pada panggilan sebelumya dan mengkalkalkulasikan kembali dengan DH shared secret. Proses key management pada ZRTP tidak berdasar kepada SIP dan pada VoIP server. Key management dilakukan secara peer-to-peer melalui paket RTP. Kelemahan dari metode Diffie-Hellman key exchange dan metode SRTP yang tidak dapat memverifikasi masing masing endpoint akan ditutupi menggunakan metode SAS. Terjadi serangan MiTM, jika pada verifikasi ditemukan nilai SAS yang berbeda.

\section{VoIP}

VoIP menggunakan teknologi jaringan IP. Hampir sama ketika mengoperasikan komputer, menggunakan TCP/IP untuk mentransfer paket dengan data. VoIP mengirimkan paket dengan audio. VoIp didesain menggunakan protokol data seperti HTTP, HTTPS, POP3/IMAP, dan SMTP yang digunakan dalam transfer paket data. VoIP dibangun menggunakan protokol suara, seperti SIP (Session Initiation Protocol), H.323, IAX (Inter- Asterisk eXchange protokol), dan RTP (Real-time Transport Protocol). Header dalam paket TCP/IP untuk data akan sama dengan untuk VoIP, termasuk frame Ethernet, alamat IP sumber, alamat IP tujuan, informasi MAC, dan 
nomor urut. Gambar 1 menunjukkan contoh bagaimana VoIP terintegrasi dengan model OSI, di mana item yang dicetak tebal adalah protokol VoIP umum.

Pada pengaturan panggilan telepom menggunakan protokol utama yang digunakan dalam VoIP yaitu SIP dan H.323 pada lapisan sesi, dan RTP pada lapisan media, bertugas menangani bagian media panggilan. Oleh karena itu, SIP dan H.323 membuat sambungan panggilan dan menyerahkannya ke RTP dalam mengirimkan media untuk panggilan tersebut. IAX adalah satusatunya protokol yang melakukan pengaturan sesi dan transfer media suara. Bagian setup untuk panggilan VoIP biasanya dilakukan dengan beberapa server pendukung, seperti SIP Proxy/Registrar dan/atau gatekeeper/gateway H.323. Setelah sesi diatur menggunakan SIP atau H.323, panggilan dikirim ke protokol media,yaitu RTP [18].

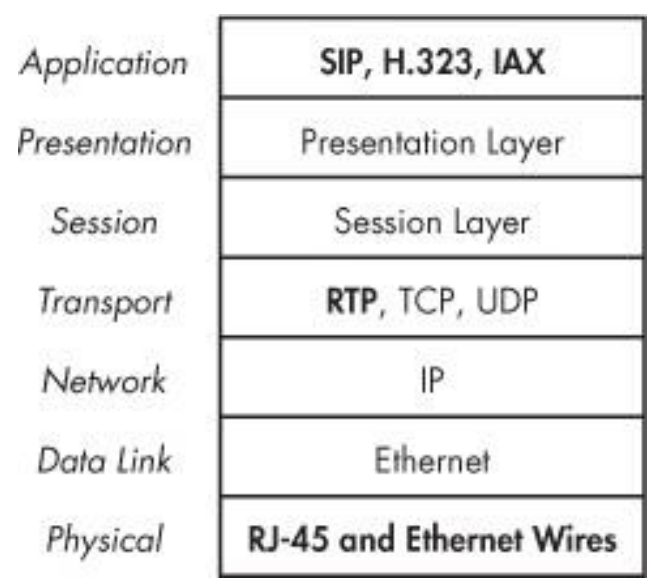

Gambar 1. VoIP dalam pemodelan OSI [18]

\section{METODE PENELITIAN}

\section{A. Blok Diagram Sistem}

Rancang bangun secure mobile IP PBX berbasis raspberry pi ini merupakan perangkat yang didesain khususnya untuk mendukung jalannya komunikasi pada saat Taruna AAU dan pendukungnya sedang melaksanakan kegiatan diluar ksatrian AAU. Perangkat komunikasi ini dapat dibawa secara flexible pada setiap kegiatan tanpa menggantungkan sinyal internet karena perangkat ini dapat berjalan dalam jaringan local area network. Raspberry pi pada alat ini merupakan mikrokomputer yang memiliki pin General-Purpose Input/Output (GPIO) yang dapat digunakan sebagai interface input dan output raspberry pi. Raspberry pi memiliki port LAN yang dapat menghubungkan raspberry pi dengan Ethernet. Dalam perancangan sistem diberikan perincian mengenai hardware dan software yang digunakan sebagai berikut:

1. Hardware

a. Server. Pada server berbasis raspberry pi 4 ini menggunakan OS CentOS 7 versi minimal CentOS dengan nama file CentOS-Userland-7-armv7hl-RaspberryPI-Minimal4-2009-sda.raw.xz.

b. Router. Jangkauan wi-fi menggunakan access point agar server dan client untuk mendapatkan akses.

c. Smartphone. Client yang terinetgrasi dengan server, dalam penelitian ini menggunakan OS android.

d. PC/Laptop. 
2. Software

a. Softswitch. Pada server perangkat menggunakan asterisk softswitch berfungsi sebagai software IP PBX jenis SIP Proxy Open Source

b. Softphone. Dalam penelitian ini client menggunakan phonerlite, jitsi dan zoiper sebagai aplikasi softphone yang dapat diunduh secara gratis melalui sumber resmi yang terpercaya.

c. Remote computing tool. Dalam penelitian ini menggunakan MobaXterm X server and SSH client merupakan aplikasi untuk melakukan akses server jarak jauh secara efisien melalui jaringan atau sistem yang berbeda.

d. Network Analyzer Tool. Berfungsi sebagai penetration testing sebelum sistem dinyatakan sebagai sistem yang aman.

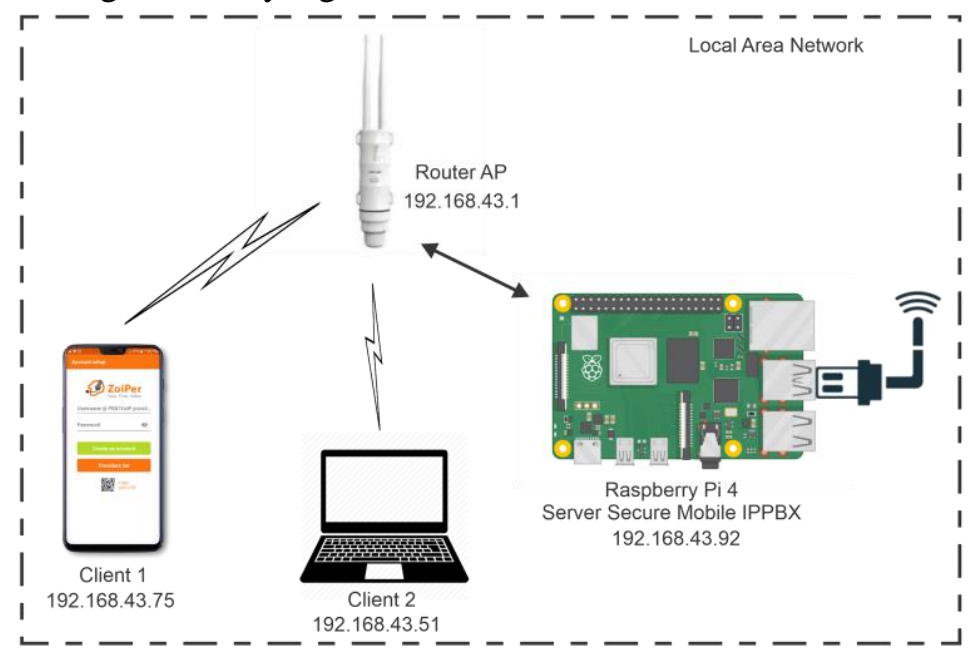

Gambar 2. Diagram blok sistem

Diagram blok sistem secure mobile IPPBX dapat dilihat pada Gambar 2. Server dibangun dalam raspberry pi yang sudah terinstalasi softswitch yaitu asterisk yang dihubungkan dengan router. Dengan demikian client bisa mendapatkan akses untuk saling berkomunikasi. Aplikasi softphone digunakan pada smartphone pada sisi client. Sistem VoIP ini menggunakan topologi star. Sistem yang didesain dengan menggunakan local area network dengan demikian user/client tetap bisa berkomunikasi walaupun sinyal internet tidak tersedia.

\section{B. Flowchart Sistem}

Pada bagian ini akan dijelaskan cara kerja sistem menggunakan flowchart. Berdasarkan pentahapan yang ditunjukkan pada Gambar 3, pada tahap pertama adalah instalasi asterisk pada sistem operasi centos berbasis raspberry pi. Konfigurasi sistem adalah langkah selanjutnya yang harus dilaksanakan. Pada langkah ini dilakukan uji coba pengecekan komunikasi antar client/user melalui server. Apakah komunikasi yang dilakukan tersebut aman atau tidak, menggunakan bantuan tool network analyzer. Jika komunikasi VoIP tidak aman atau terjadi penyadapan maka kembali kepada konfigurasi sistem dengan penambahan protokol keamanan ZRTP dan menggunakan TLS. Selanjutnya dilakukan komunikasi VoIP kembali melalui server. Jika komunikasi berjalan dengan lancar dan aman (penetration testing), pengecekan menggunakan tool network analyzer maka rancang bangun secure mobile IP PBX siap untuk di operasikan dalam rangka mendukung back up komunikasi setiap kegiatan Taruna AAU teruatam saat kegiatan luar. 


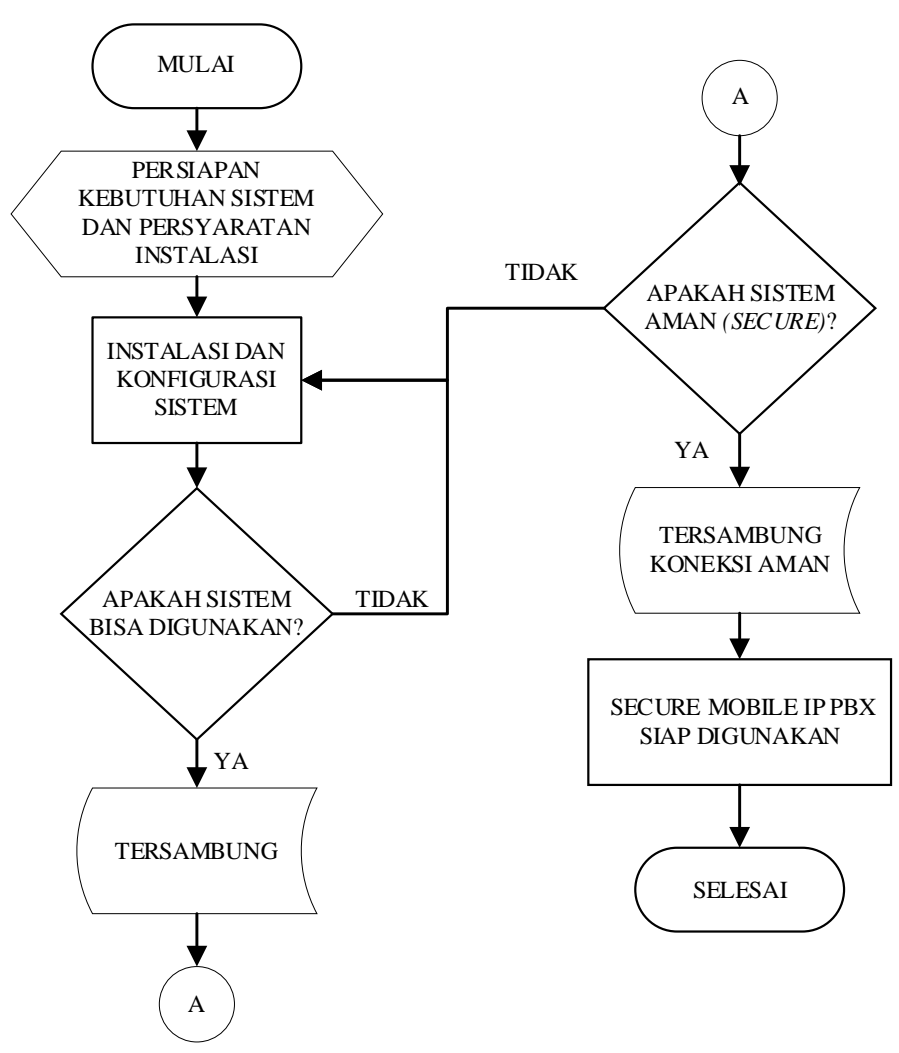

Gambar 3. Flowchart sistem

\section{IMPLEMENTASI MODEL DAN PEMBAHASAN}

Perancangan sistem yang telah dilakukan, selanjutnya pada bagian keempat ini berupa implementasi model dan pembahasan. Dalam perancangan sistem akan terbagi menjadi dua skenario yaitu perancangan sistem sebelum dilengkapi menggunakan protokol keamanan dan setelah dilengkapi protokol ZRTP.

\section{A. Instalasi Sistem}

1. Server menggunakan raspberry pi 4 model B RAM 4GB. VoIP server yang digunakan yaitu asterisk versi 13.38.3 yang berjalan pada sistem operasi Linux CentOS. Alamat repository asterisk 13 yaitu https://downloads.asterisk.org/pub/telephony/asterisk/old-releases/asterisk13.38.3.tar.gz. Repository ini ditambahkan ke dalam sistem operasi dijalankan dengan perintah 'wget'.Hasil instalasi server VoIP ditunjukan pada Gambar 4.

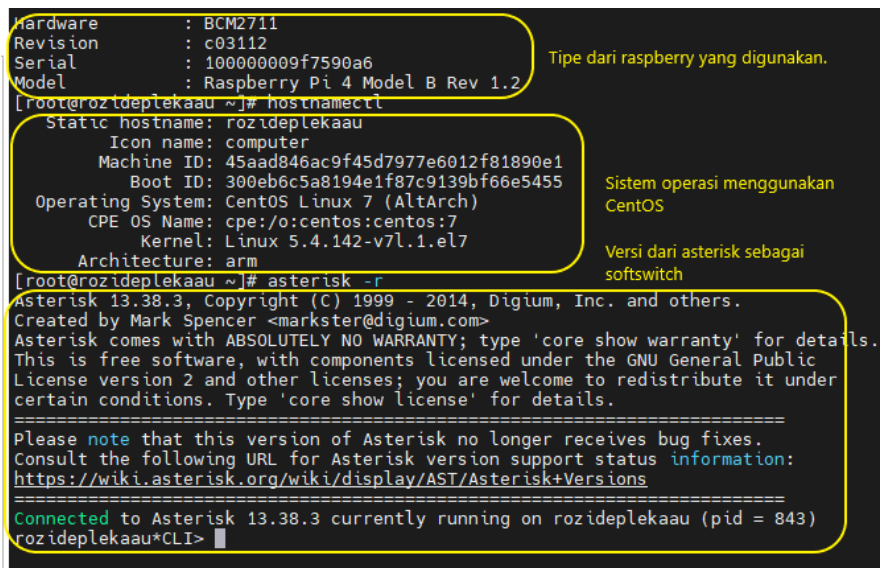

Gambar 4. Spesifikasi dan hasil instalasi softswitch asterisk

Rancang Bangun Secure Mobile PABX Berbasis Raspberry Pi Dalam Mendukung Komunikasi Kegiatan Luar Taruna Akademi Angkatan Udara (M. Kharrel Dwiadamajati) 
2. Pengalamatan pada VoIP disebut SIP ID. Pembuatan SIP ID asterisk pada file letc/asterisk/conf kemudian dilanjutkan dengan cara mengedit file sip_users.conf. File conf/sip_users.conf merupakan file konfigurasi dari GNU asterisk dan memiliki tipe XML. SIP ID tersimpan di server serta dapat ditambah dan dikurangi sesuai dengan kebutuhan, untuk konfigurasinya dalam penelitian ini ditunjukkan pada Gambar 5.

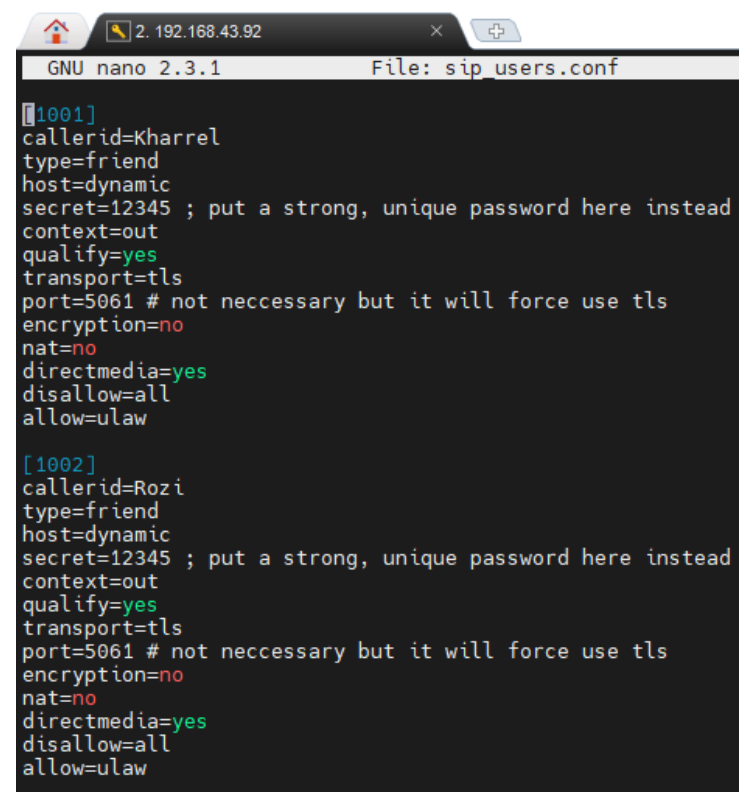

Gambar 5. Konfigurasi file user

3. Implementasi pada VoIP Client. Client disini dapat menggunakan PC/laptop dan smartphone. Beberapa aplikasi softphone yang tersedia baik untuk instalasi pada PC/laptop dan smartphone yang digunakan pada penelitian ini adalah jitsi,zoiper dan phonerlite. Untuk pengalamatan SIP ID pada client ditunjukkan pada Tabel II.

TABEL II

SIP ID

\begin{tabular}{|c|c|c|}
\hline \hline SIP ID & IP Address & Keterangan \\
\hline 1001 & $192,168.43 .51$ & Client \\
\hline 1002 & $192,168.43 .75$ & Client \\
\hline
\end{tabular}

\section{B. Pengujian Sistem Tanpa Protokol Keamanan}

Pada tahap ini dilakukan pengujian terhadap sistem komunikasi VoIP yang belum diberikan pengamanan dan yang sudah memiliki pengamanan dengan ZRTP. Tujuan dari pengujian ini adalah untuk mengetahui tingkat keamanan dari masing masing sistem VoIP. Berikut ini adalah penjelasan langkah pengujiannya:

1. Buka wireshark lalu pilih menu capture lalu options, lalu akan muncul daftar interface. Pilih interface yang akan dianalisis network traffic-nya. Pilih menu capture lalu start untuk memulai proses packet sniffing. Proses ini dilakukan ketika proses komunikasi VoIP berlangsung sampai dengan selesai. Saat komunikasi VoIP berlangsung akan terlihat paket SIP dan RTP pada jendela wireshark seperti pada Gambar 6. 


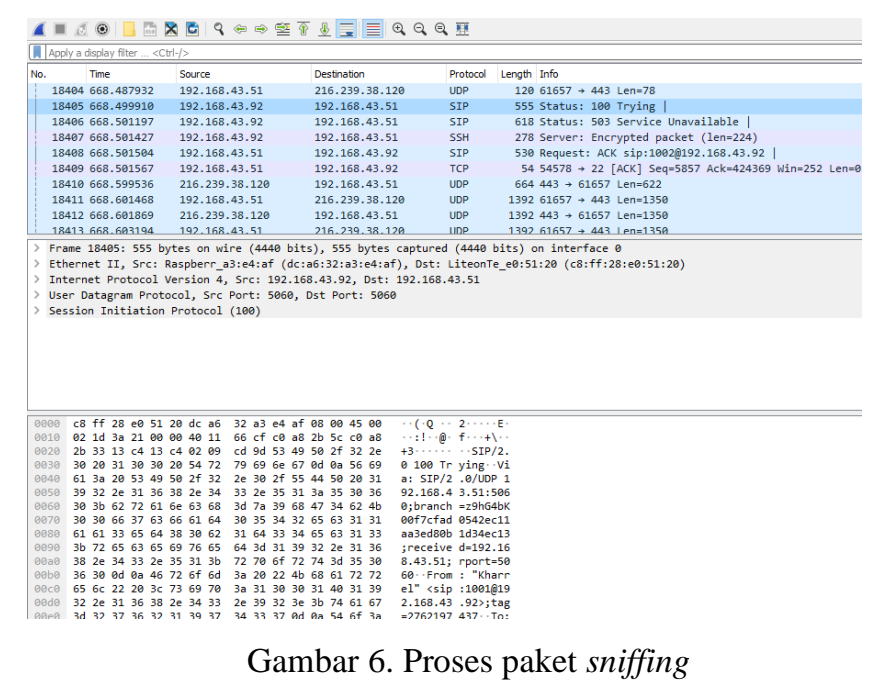

2. Ketika pada jendela wireshark tidak menampilkan lagi paket RTP atau SIP, dapat disimpulkan komunikasi VoIP telah selesai. Selanjutnya adalah mendecode paket SIP dengan memilih menu Telephony lalu Voip Calls. Wireshark akan menampilkan komunikasi VoIP yang terdeteksi seperti pada Gambar 7. Pada komunikasi VoIP, lalu tombol "Play Stream" berfungsi artinya ada komunikasi yang dapat didengarkan atau komunikasi VoIP terdeteksi oleh attacker.

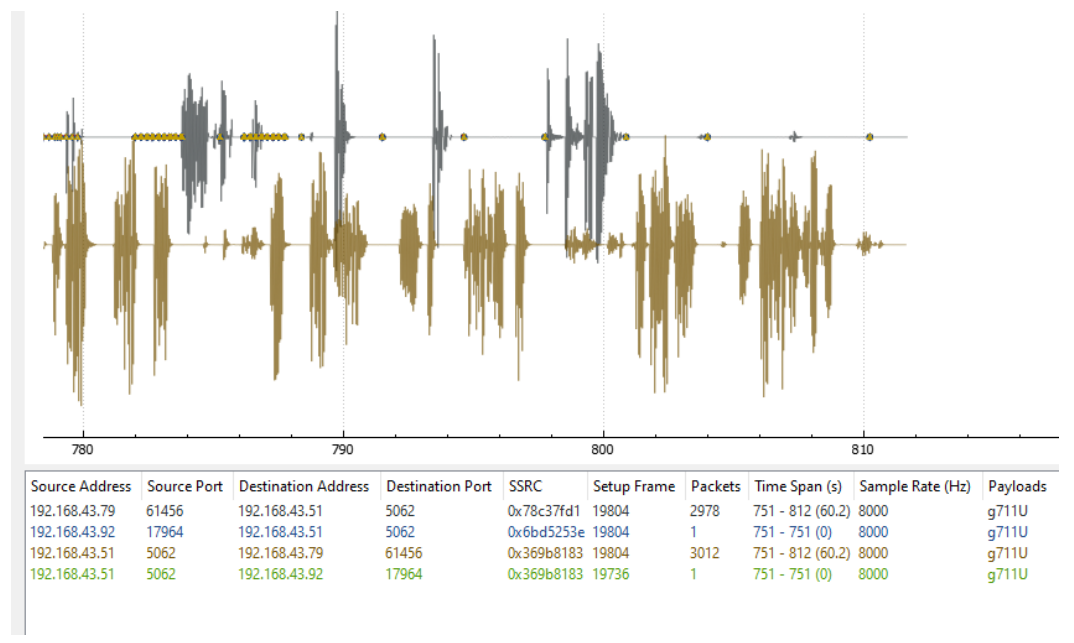

Gambar 7. Hasil komunikasi VoIP

\section{Pengujian Sistem Dengan Protokol Keamanan ZRTP dan TLS}

Pada pengujian VoIP server yang sudah diamankan dengan mengaktifkan protokol Transport Layer Security (TLS) dan ZRTP menggunakan metode dan tools yang serupa dengan pengujian VoIP server tanpa pengamanan. Pada skenario ini, proses packet sniffing dilakukan saat komunikasi VoIP berlangsung. Penjelasan langkah-langkahnya adalah sebagai berikut:

1. User A melakukan panggilan dengan memilih nomor tujuan SIP ID user B pada field keypad or destinatiom number di aplikasi PhonerLite dan klik tombol Call. Pada user B akan muncul panggilan dari user A, terima panggilan dengan mengklik icon telephone dan mulai perbincangan ditunjukkan pada Gambar 8. Pada tahap ini, muncul tanda ikon TLS dan SAS yang menandakan pengamanan ZRTP telah terbentuk. 


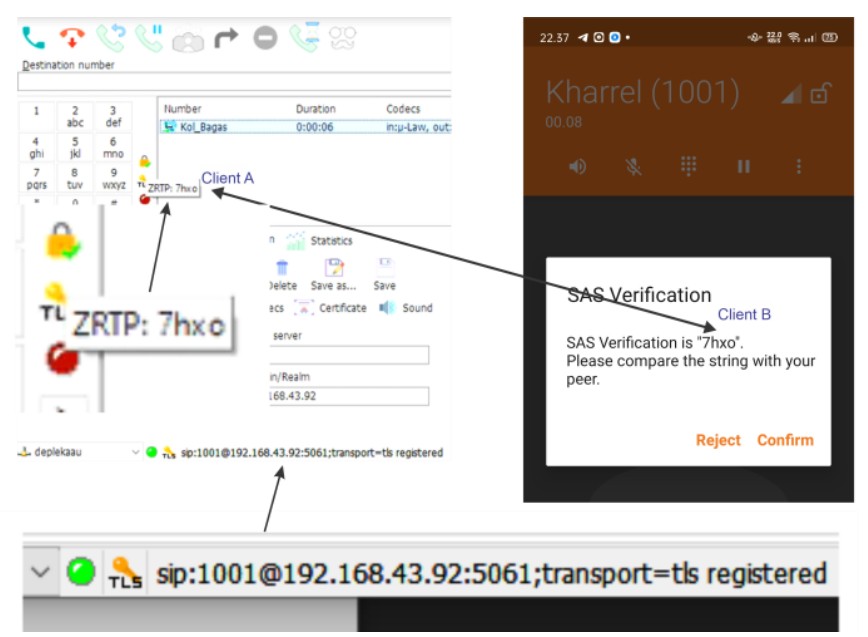

Gambar 8. Tampilan TLS dan SAS verification

2. Pada jendela wireshark, klik capture lalu pilih start untuk memulai packet sniffing. Akhiri panggilan dengan mengklik icon telephone yang berwarna merah. Lalu kembali ke jendela wireshark untuk menghentikan proses packet sniffing dengan mengklik menu capture pilih stop. Selanjutnya klik menu telephony lalu pilih VoIP Calls untuk melihat komunikasi VoIP yang terdeteksi oleh wireshark seperti ditampilkan pada Gambar 9. Pada komunikasi VoIP, lalu tombol "Play Stream" tidak berfungsi artinya tidak ada komunikasi yang dapat didengarkan atau komunikasi voip melalui protokol ZRTP dapat berfungsi dengan baik.

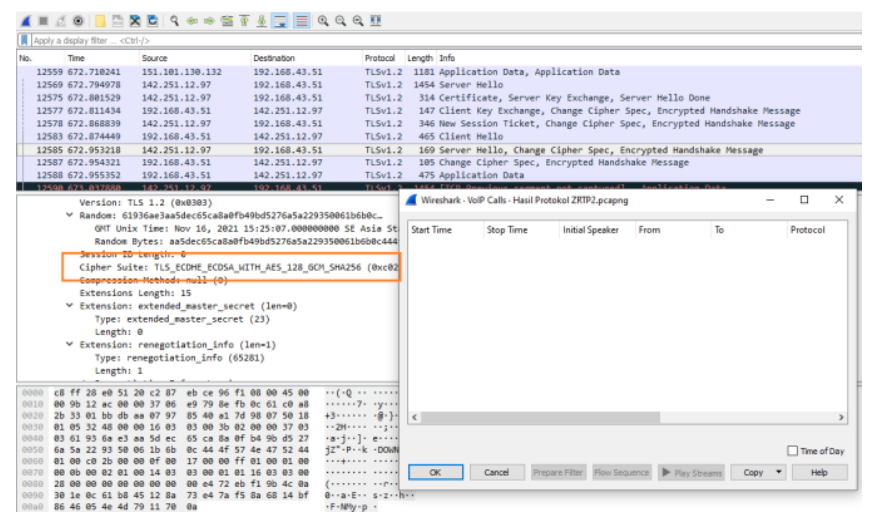

Gambar 9. Komunikasi VoIP tidak terdeteksi

\section{Analisis Sistem}

Berdasarkan skenario pengujian, perbandingan dan pengukuran sistem VoIP diatas dapat diperoleh analisis performa sebagai berikut:

1. Pada skenario pertama, server berbasis raspberry pi dapat digunakan sebagai mobile IP PBX menggunakan sistem operasi centos dengan softswitch asterisk sebagai pengganti mesin PBX konvensional. Namun pada skenario tersebut jaringan VoIP masih belum aman dengan adanya eavesdropping berupa hasil tangkapan komunikasi VoIP.

2. Pada skenario kedua, dengan menambahkan fitur serta mengaktifkan protokol TLS dan ZRTP pada softswitch asterisk. Setelah dimplementasikan, kandungan isi komunikasi dapat 
terjaga dengan baik dengan ditandai tidak adanya hasil tangkapan komunikasi VoIP melalui hasil rekaman network analyzer tools.

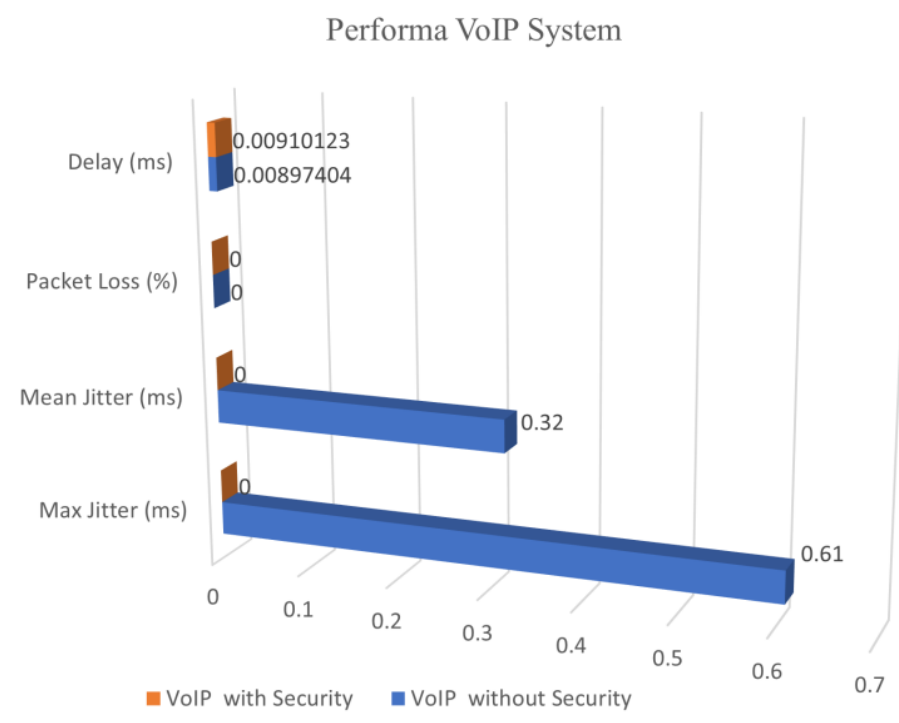

Gambar 10. Grafik QoS Komunikasi VoIP

Berdasarkan Gambar 10 Quality of Service (QoS) sistem VoIP yang berisi data hasil pengukuran jitter, packet loss dan delay. Untuk jitter pada sistem VoIP tanpa pengamanan pengukuran masih dapat dilakukan, namun untuk sistem VoIP dengan pengamanan menunjukkan angka 0 dikarenakan tidak ada tangkapan hasil komunikasi VoIP menggunakan network analyzer tool. Pengukuran packet loss menghasilkan nilai $0 \%$ yang artinya tidak ada paket yang hilang selama komunikasi VoIP berlangsung. Sedangkan untuk pengukuran delay menunjukkan bahwa sistem VoIP dengan pengamanan menghasilkan delay lebih lama daripada sistem VoIP tanpa pengamanan. Berdasarkan rekomendasi ITU G.114 merekomendasikan standar delay. Delay dengan range antara $0-150 \mathrm{~ms}$ masih dapat diterima oleh kebanyakan aplikasi suara [19].

\section{KESIMPULAN}

Server VoIP berbasis raspberry pi 4 ini merupakan pilihan jembatan komunikasi yang dapat digunakan saat berada pada medan memiliki sumber daya yang terbatas. Dengan tetap menjaga kandungan isi komunikasi, perangkat ini dilengkapi dengan protokol keamanan yaitu TLS dan ZRTP. TLS berfungsi mengenkripsi jaringan lalu lintas sinyal dari server sampai client. Dengan mengaktifkan ZRTP akan mengenkripsi media atau data secara end to end.

Perlu ada penelitian lanjutan yang dilakukan mengenai beban tentang phone lines and concurrent calls yang sanggup digunakan pada raspberry pi.

\section{UCAPAN TERIMA KASIH}

Ucapan Terima Kasih kepada Gubernur Akademi Angkatan Udara, Marsda TNI Nanang Santoso yang telah memberikan izin untuk melakukan penelitian, mengakses sarana dan prasana serta fasilitas untuk mendukung kegiatan penelitian.

\section{REFERENSI}

[1] "Peraturan Panglima Tentara Nasional Indonesia Nomor 15 Tahun 2019 Tentang Organisasi dan Tugas Akademi TNI Angkatan Udara.pdf."

[2] "Visi Misi - AKADEMI ANGKATAN UDARA." https://aau.ac.id/?page_id=22 (accessed Oct. 24, 2021). 
[3] T. Surasak and C.-H. Scott Huang, "Enhancing VoIP Security and Efficiency using VPN," in 2019 International Conference on Computing, Networking and Communications (ICNC), Honolulu, HI, USA, Feb. 2019, pp. 180-184. doi: 10.1109/ICCNC.2019.8685553.

[4] T. De Pessemier, L. Martens, and W. Joseph, "A large-scale, long-term, user-centric evaluation of a commercial voice-over-IP application," in 2014 IEEE International Symposium on Broadband Multimedia Systems and Broadcasting, Beijing, China, Jun. 2014, pp. 1-6. doi: 10.1109/BMSB.2014.6873464.

[5] I.-L. Lin, Y.-S. Yen, B.-L. Wu, and H.-Y. Wang, "VoIP Digital Evidence Forensics Standard Operating Procedure (DEFSOP)," in 2010 International Conference on Broadband, Wireless Computing, Communication and Applications, Fukuoka, Nov. 2010, pp. 407-412. doi: 10.1109/BWCCA.2010.105.

[6] L. Carvajal, L. Chen, C. Varol, and D. Rawat, "Detecting unprotected SIP-based voice over IP traffic," in 2016 4th International Symposium on Digital Forensic and Security (ISDFS), Little Rock, AR, USA, Apr. 2016, pp. 44-48. doi: 10.1109/ISDFS.2016.7473515.

[7] D. Schürmann, F. Kabus, G. Hildermeier, and L. Wolf, "Wiretapping End-to-End Encrypted VoIP Calls: Real-World Attacks on ZRTP," Proc. Priv. Enhancing Technol., vol. 2017, no. 3, pp. 4-20, Jul. 2017, doi: 10.1515/popets-2017-0025.

[8] R. Bresciani and A. Butterfield, "A formal security proof for the ZRTP Protocol," in 2009 International Conference for Internet Technology and Secured Transactions, (ICITST), London, Nov. 2009, pp. 1-6. doi: 10.1109/ICITST.2009.5402595.

[9] THE OFFICIAL Raspberry Pi Beginner's Guide: How to use your new computer. 2020.

[10] A. Avorizano and A. Fajar, "Penggunaan Raspberry Pi sebagai Alternatif Micro Controller pada Robot Sederhana," vol. 6, no. 2, p. 4, 2013.

[11] "raspberry-pi-4-product-brief.pdf." https://datasheets.raspberrypi.com/rpi4/raspberry-pi-4-productbrief.pdf (accessed Nov. 03, 2021).

[12] Y. Yuniati, H. Fitriawan, and D. F. J. Patih, "ANALISA PERANCANGAN SERVER VOIP (VOICE INTERNET PROTOCOL) DENGAN OPENSOURCE ASTERISK DAN VPN (VIRTUAL PRIVATE NETWORK) SEBAGAI PENGAMAN JARINGAN ANTAR CLIENT," vol. 12, no. 1, p. 10, 2014.

[13] B. Jackson and C. Clark, Asterisk Hacking. Books24x7.com, 2007. [Online]. Available: https://books.google.co.id/books?id=Ml1EwgEACAAJ

[14] R. Bryant, Asterisk: the definitive guide, Fourth edition. Beijing : Sebastopol: O'Reilly, 2013.

[15] M. Petraschek, T. Hoeher, O. Jung, H. Hlavacs, and W. Gansterer, "Security and Usability Aspects of Man-in-the-Middle Attacks on ZRTP," Security ..., p. 20.

[16] P. Zimmermann, A. Johnston, and J. Callas, "ZRTP: Media Path Key Agreement for Unicast Secure RTP,” RFC Editor, RFC6189, Apr. 2011. doi: 10.17487/rfc6189.

[17] D. Perez-Botero and Y. Donoso, "VoIP Eavesdropping: A Comprehensive Evaluation of Cryptographic Countermeasures," in 2011 Second International Conference on Networking and Distributed Computing, Beijing, China, Sep. 2011, pp. 192-196. doi: 10.1109/ICNDC.2011.46.

[18] H. Dwivedi, Hacking VoIP: protocols, attacks, and countermeasures. San Francisco: No Starch Press, 2009.

[19] A. Rachmat, “17-ANALISIS KINERJA VOICE OVER INTERNET PROTOCOL PADA MOBILE AD-HOC NETWORK,” p. 15. 